\title{
Hélène Romeyer (dir.) : La santé dans l'espace public
}

\section{Patrice De La Broise}

\section{(2) OpenEdition}

1 Journals

Édition électronique

URL : http://journals.openedition.org/edc/2648

DOI : $10.4000 /$ edc. 2648

ISSN : 2101-0366

Éditeur

Université de Lille

\section{Édition imprimée}

Date de publication : 1 juin 2011

Pagination : 182-184

ISBN : 978-2-917562-05-5

ISSN : 1270-6841

Référence électronique

Patrice De La Broise, " Hélène Romeyer (dir.) : La santé dans l'espace public », Études de communication [En ligne], 36 | 2011, mis en ligne le 20 juillet 2011, consulté le 22 septembre 2020. URL : http:// journals.openedition.org/edc/2648; DOI : https://doi.org/10.4000/edc.2648 


\title{
Hélène Romeyer (dir.) : La santé dans l'espace public
}

\author{
Patrice De La Broise
}

\section{RÉFÉRENCE}

Hélène Romeyer (dir.) : La santé dans l'espace public, Presses de l'EHESP, 2010.

1 Parmi les grandes questions de société, la santé compte sans doute parmi les plus médiatisées. Mais ne s'agit-il que de médiatisation? Les nombreuses crises sanitaires et les controverses suscitées par les politiques publiques ne font pas seulement l'objet d'une importante couverture médiatique. Pas plus qu'elles ne sont réductibles aux cadres discursifs des politiques publiques ou de la communication scientifique. L'ouvrage collectif dirigé par Hélène Romeyer vise précisément à discerner, entre les discours sur la santé et les discours de la santé, différentes stratégies, formes et figures discursives à l'œuvre dans un « espace public partiel » que semblent se disputer le politique, le journaliste et le citoyen.

2 Reprise éditoriale d'un colloque tenu à Rennes en 2008, La santé dans l'espace public ouvre d'abord sur les rapports entre politiques publiques de santé et communication. Une analyse comparée des campagnes de dépistage du cancer met ainsi en perspective les traductions discursives de politiques publiques saisies dans leurs contextes sociohistoriques respectifs (États-Unis, Royaume-Uni, France). La comparaison des campagnes de prévention sur Internet leur reconnaît bien quelques similitudes, eu égard à une mondialisation conjointe des standards de santé et de la publicisation électronique. Mais l'analyse montre surtout combien les contrats et stratégies de communication diffèrent d'un contexte national à l'autre. Preuve sans doute que la "politique du discours", selon l'expression de Caroline Olivier-Yanniv, participe pleinement de l'action publique. Tandis qu'au Québec une rhétorique prométhéenne use de l'argument technologique pour réformer le système de santé, le suivi des campagnes institutionnelles françaises de lutte contre le tabac révèle le paradoxe 
discursif et les enjeux politiques d'une communication publique versatile et, au demeurant, inefficace. Dans un autre registre, Pauline Grison et Daniel Jacobi attirent notre attention sur ces sortes de prescriptions ordinaires - «manger au moins cinq fruits et légumes par jour »- qui traduisent en normes comportementales ce que la science recommanderait seulement, faute de preuve. Dans le processus de vulgarisation qui mène au slogan publicitaire, comme facilitation d'une "croyance", il reste décidément "peu de place à l'expression du doute et de la prudence scientifique » (p. 87).

3 Les pouvoirs publics ne sont pas seuls en cause. Et l'on ne peut parler de publicisation sans interroger le traitement journalistique des questions de santé. En la matière, la deuxième partie de l'ouvrage montre combien les médias ne se contentent pas de relayer les politiques publiques, ni même de retranscrire les avancées de la recherche médicale ; ils « construisent et orientent le débat public ». Mais, s'interrogera Bernard Miège dans sa postface, «suffit-il que les médias interviennent pour que l'on se trouve en présence d'un espace public?» (p. 208). À lire l'article que Loïc Ballarini consacre aux publications annuelles des " palmarès des hôpitaux », on peut en douter. Et l'auteur de s'interroger, de nous interroger, sur cet étrange rituel journalistique qui, sous prétexte d'éclairer le citoyen, contribue plus certainement à l'accomplissement des réformes néolibérales du système de santé. Entre les lignes, c'est l'éthique journalistique qui est mise en débat, jusque dans le traitement narratif et émotionnel des questions les plus sensibles. Questions de vie et de mort, quand il s'agit de dons d'organes, qui interrogent la posture et l'éthique professionnelle du journaliste. À charge, ou à décharge, Jérôme Thomas et Michel Watin nous montrent aussi combien la prétention critique de la presse reste tributaire des représentations sociales et des enjeux économiques qui la dépassent.

4 Mais c'est ailleurs, aux frontières incertaines des espaces "politique " et «médiatique », que nous transportent les dernières contributions de l'ouvrage. Là où d'autres acteurs, associatifs notamment, créent l'événement et tirent parti de l'Internet pour " exister dans l'espace public ». Certains œuvrent ainsi à la production et à la diffusion d'information sur les maladies rares; d'autres organisent la " prise de parole collective des patients». Tous en appellent à la reconnaissance des malades comme parties prenantes, avec ce que cette participation suppose d'engagement et, parfois, d'instrumentalisation, comme en témoignent l'enrôlement ou la "construction d'une nouvelle figure du patient » dans le programme national de lutte contre le Sida au Cambodge décrit par Ève Bureau.

$5 \mathrm{Au}$ terme de cette lecture, il faut saluer la contribution éclairante de La santé dans l'espace public à un triple questionnement sur les enjeux, les modalités et les acteurs d'une publicisation des questions sanitaires. Contribution d'autant plus louable que, sur un sujet aussi vaste et controversé, la réunion de quelques recherches scientifiques récentes constitue toujours un exercice éditorial périlleux. Le péril tient ici au fait que l'espace public partiel se trouve plus souvent convoqué que discuté dans sa qualification (politique, médiatique, sanitaire ?) et sa lecture communicationnelle. Mais cette critique de fond doit être prise pour un encouragement, comme un appel à une suite éditoriale nécessaire. D'autant qu'en ce domaine sensible de la Santé Publique, la contribution des sciences sociales, notamment des sciences de l'information et de la communication, est très attendue. 


\section{AUTEUR}

\section{PATRICE DE LA BROISE}

Maître de conférences en Sciences de l'Information et de la Communication,Laboratoire GERiiCO (EA4073) - Université Lille 3 